\title{
The association between VO2max and heart rate of casting industry workers
}

\author{
Moghiseh M, MSc${ }^{1}$, Habibi E, $\mathrm{PhD}^{2 *}$, Aramesh N, $\mathrm{MSc}^{3}$, Hasanzadeh A, BSc${ }^{4}$, Khorvash MK, BSc ${ }^{5}$, \\ Poorrahmatian $\mathrm{AH}, \mathrm{BSc}^{6}$
}

1- MSc Student, Dept., of Occupational Health, School of Public Health, Isfahan University of Medical Sciences, Isfahan, Iran. 2- Associate Prof., Dept., of Occupational Health, School of Health, Isfahan University of Medical Science, Isfahan, Iran. 3- PhD Student, Inorganic Chemistry, Yasuj University, Yasuj, Iran. 4- BSc, Dept. of Biostatistics, School of Health, Isfahan University of Medical Sciences, Isfahan, Iran. 5- BSc, Isfahan Casting Industry, Isfahan, Iran. 6- BSc, Dept., of Occupational Health, School of Health, Tehran University of Medical Sciences, Tehran, Iran.

\begin{abstract}
Received: August 2013, Accepted: January 2014

Background: To establish a balance between work (physical exercise) and human, the aerobic capacity (VO2max) could be used as a measure. Assessing the heart rate in association to physiological symptoms is the most commonly used tool for the assessment of fatigue during physical exercise. This study aimed to investigate the association between the aerobic capacity and the heart rate of workers from the casting industry.

Materials and Methods: The subjects were 200 male workers selected from casting industry in Isfahan using random sampling method. The subjects were examined using ergometer in accordance with Astrand 6 minutes cycle test protocol, Then, the VO2max was estimated using the formula proposed by American College of Sports Medicine (ACSM). The heart rates were monitored and recorded automatically. Finally, the results were analyzed by SPSS 20 statistical software package.

Results: The results illustrated that there was a strong correlation between heart rate (HR) and VO2max $(\mathrm{r}=0.991, \mathrm{P}<0.001)$. The regression analysis of the quadratic equation indicated that there was a significant association between the $\mathrm{VO} 2 \mathrm{max}$ and the heart rate.

Conclusion: As the results indicated there was a strong association between heart rate and VO2max, indicating the fact that with the increase in heart rate during physical activity, aerobic capacity is reduced, and the heart rate could be used as a prediction measure to estimate VO2max.
\end{abstract}

Keywords: Worker, Heart Rate, Castings, Industry.

\section{Introduction}

The main purpose of ergonomics is to make equilibrium between man and the environment. To assess the effectiveness of an ergonomic intervention schedule, the particular tools are needed to gather information on the compatibility (1).

One important perspective of the compatibility between man and the environment is the physical perspective. Assessing the physical and physiological characteristics of human, it is possible to assign him to a task based on his physiological tolerance limits. Therefore, by addressing measuring metabolism and oxygen consumption during work, Marties noted that all physical practices should be done within the human aerobic capacity. Currently, the aerobic capacity has been known as the maximal capacity to accomplish the work (2). VO2max (also maximal oxygen consumption, maximal oxygen uptake, peak oxygen uptake, or maximal aerobic capacity) is the maximum capacity of an individual's body to transmit through circulatory system and use oxygen in motor muscles (3).

\footnotetext{
* Corresponding author: Ehsan-Allah Habibi, Dept., of Occupational Health, School of Public Health, Isfahan University of Medical Science, Isfahan, Iran. Email: habibi@hlth.mui.ac.ir
} 
Aerobic Fitness was our ability to take in and use oxygen (4) to produce energy and we have accepted the aerobic capacity as the maximal capacity during work shifts. Nowadays, scientists believe that the ability to perform physical exercise should be determined using the aerobic capacity (2). There are 2 methods for measuring the aerobic capacity which are divided into two groups: direct methods and indirect methods. The direct methods include using the treadmill, ergometer, and step tests, while the indirect methods include charts and formulas of Astrand and physiological (e.g., heart rate) and subjective (e.g., rating of perceived exertion) variables. In fact it is worth noting that the direct methods are more accurate because they are more expensive and need trained technicians for setting up and using equipments which is also time consuming; on the contrary, the indirect methods are useful and effective for assessing aerobic capacity in the industries and have no such limitations (5).

Consequently, we utilized heart Rate (HR) as an indirect method for assessing the aerobic capacity (6). The condition of workers in our country and also other developing countries is important, since in these countries, most industrial processes are performed in the form of semi-mechanized; the workers are forced to do the jobs manually.

To prevent early deterioration of workforce resulting in low efficiency, it is necessary to determine the fitness between the individual and the work. There has been no comprehensive study done on the physical exercise capacity of Iranian workers, as a result, there is no detailed information in this area; (7-9) perhaps because of the high cost of technician training to operate the special equipments of direct methods such as ergometer, which isn't cost-effective and affordable for the industry. Nevertheless, a few studies have been done abroad on the worker populations by using physiological and subjective methods to assess the oxygen consumption of the workers in physical exercises. These studies aimed to assign individuals to the tasks on the basis of their physiological tolerance limits in accordance with ergonomics principles. Therefore, the current study intends to use the results of the rating of perceived exertion of physical exercise (ergometer) and heart rate measurements to estimate the level of the individual's aerobic capacity and finally to determine the association between aerobic capacity and heart rate measurements.

\section{Materials and Methods}

In this descriptive study the subjects were 200 male workers from metal components manufacturers (casting industry) in Isfahan selected using random sampling method. The subjects were tested with a time schedule of maximum 10 subjects per day. The ergometer and Astrand protocol were used to determine the aerobic capacity.

The uses of these devices were to create workload on foreign and domestic studies on workers (10-13).

To perform the test based on the Astrand protocol (14-16), on the worker with light clothing (17) then, 25 watt per minute was added to the workload (heaviness of pedal) (18); and at the end of each stage, the heart rate using the sports tester was measured during the last 15 seconds $(19,20)$. Next, VO2max will be calculated in $\mathrm{ml} \cdot \mathrm{kg}^{-1} \cdot \mathrm{min}^{-1}$ using ACSM formula (21).

$$
\begin{aligned}
& V O 2 \max (\mathrm{ml} / \mathrm{kg} / \mathrm{min}) \\
& =V 02 \frac{(220-a g e-73-(\operatorname{sex}(10))}{H R-73-(\operatorname{sex}(10))}
\end{aligned}
$$

Vo2= submaximal VO2 $(\mathrm{ml} / \mathrm{kg} / \mathrm{min})$ from final stage

>> VO2 $(\mathrm{ml} / \mathrm{kg} / \mathrm{min})=((1.8($ workrate $)) / \mathrm{BW})+7$

Sex $=0$ for women and 1 for men

$\mathrm{HR}=$ steady state HR from final stage 
The ergometer TUNTURI model (Finland) was used for Astrand Cycle Test.

To undertake the test: First, by coordinating and corresponding metal industries (casting industry) several manufacturers were invited to participate in the study. Second, some of the workers were removed from the population due to the following reasons: Absence, not willing to participate in the study, cardiovascular diseases and respiratory diseases) (22). Finally, the results were analyzed by SPSS 20 statistical software package.

Table 1: Individual characteristics of the subjects $(n=200)$

\begin{tabular}{|c|c|c|}
\hline Item & Mean (SD) & Min - Max \\
\hline Age (years) & $33.17(7.76)$ & $17-50$ \\
\hline Weight (Kg) & 72 (10.07) & $52-100$ \\
\hline Height (cm) & $174.15(6.24)$ & $158.5-188$ \\
\hline BMI & $23.87(2.95)$ & $16.9-31.4$ \\
\hline $\begin{array}{l}\text { Work experience } \\
\text { (years) }\end{array}$ & $6.67(5.23)$ & $0.49-25$ \\
\hline \multirow{2}{*}{ Join the Club } & Yes & $39(19.5 \%)$ \\
\hline & No & $161(80.5 \%)$ \\
\hline \multirow{2}{*}{ Marital Status } & Married & $163(181.5 \%)$ \\
\hline & Single & $37(18.5 \%)$ \\
\hline \multirow{3}{*}{ Education } & Under Diploma & $151(75.5 \%)$ \\
\hline & Under B.S. & $41(20.5 \%)$ \\
\hline & Under M.S. & $8(4 \%)$ \\
\hline \multirow{2}{*}{ Drug Abuse } & Yes & $78(39 \%)$ \\
\hline & No & $122(61 \%)$ \\
\hline
\end{tabular}

\section{Results}

The average dry bulb temperature of the test environment and wet bulb temperature were $26^{\circ} \mathrm{C}$ and $21^{\circ} \mathrm{C}$ respectively. All the subjects were male, comprising of $67.5 \%$ (n $=135)$ workers; $13.5 \% \quad(n=27)$ official personnel; $7 \% \quad(n=14)$ personnel of engineering division; $3 \%(n=6)$ personnel of procurement division; $2.5 \%(\mathrm{n}=5)$ personnel of quality control unit; $3 \%(n=6)$ personnel of security and guarding; and 3.5\% ( $\mathrm{n}=7)$ related to storage division.

Pearson correlation test showed that there is a strong significant relationship between aerobic capacity and heart rate $(r=-0904$, $\mathrm{P}<0.005)$.

Table 1 shows several studied demographic and individual characteristics. The measurements of heart rate, aerobic capacity at the end of each minute are presented in Table 2.

Table 2: Means and Standard Deviations of HR, VO2max, during resting and the end of each minute $(n=200)$

\begin{tabular}{ccc}
\hline Variable & & \\
\hline $\begin{array}{c}\text { Time of } \\
\text { measurement }\end{array}$ & $\begin{array}{c}\text { HR } \\
\text { Mean (SD) }\end{array}$ & $\begin{array}{c}\text { VO2max } \\
\text { Mean (SD) }\end{array}$ \\
Resting & $80.14(8.48)$ & - \\
End of min. 1 & $100.87(8.33)$ & $60.29(33.85)$ \\
End of min. 2 & $111.96(8.61)$ & $34.93(12.90)$ \\
End of min. 3 & $122.74(7.64)$ & $25.88(5.99)$ \\
End of min. 4 & $129.73(6.17)$ & $23.17(2.68)$ \\
End of min. 5 & $132.50(4.33)$ & $22.96(1.27)$ \\
End of min. 6 & $131.5(4.93)$ & $23.84(0.51)$ \\
\hline
\end{tabular}


As tables 2 indicates there is a stronger significant relationship between heart beat and the aerobic capacity. However, simple linear regression analysis illustrated that there is significantly a linear relationship (vo2max $=404.56-0.648(\mathrm{hr})$ ) between the aerobic capacity and heart beat $(\mathrm{R} 2=0.72, \mathrm{P}$ $<0.0001)$. Further, the quadratic equation

$$
\begin{aligned}
(\text { VO2max } & =404.56-5.62(h r) \\
& \left.+0.021(h r)^{2}\right)
\end{aligned}
$$

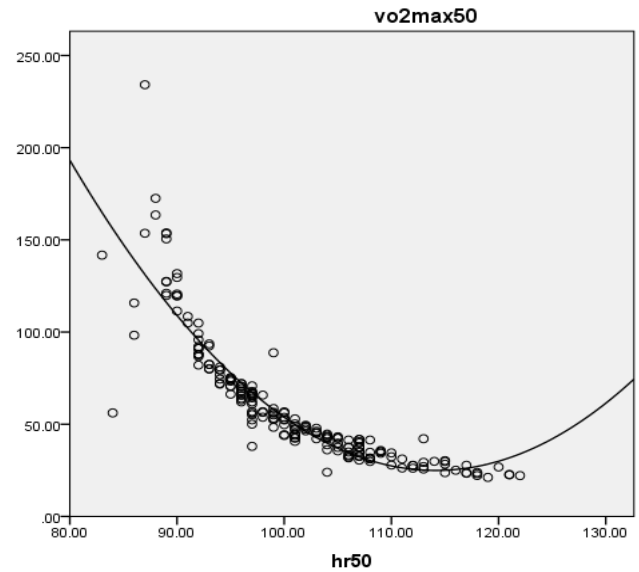

Figure 1: The association between HR and VO2max at the end of $\min .2(n=200)$

$$
\begin{aligned}
\text { VO2max } & =404.56-5.62(h r) \\
& +0.021(h r)^{2}
\end{aligned}
$$

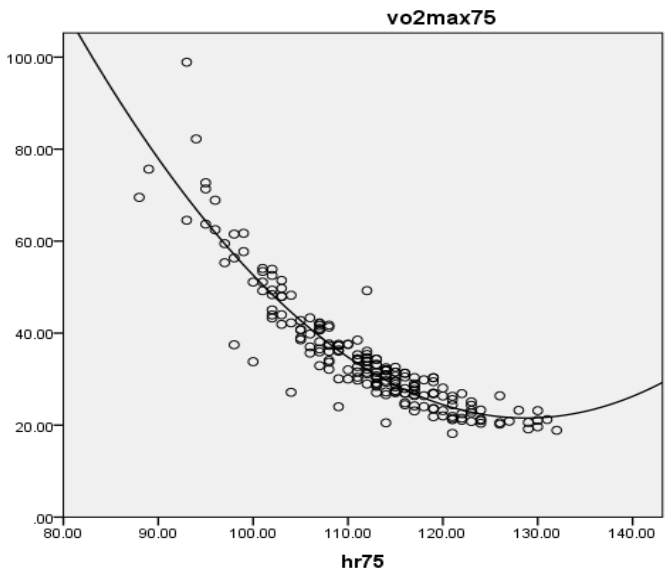

Figure 2: The association between HR and VO2max at the end of $\min .3(n=200)$

$$
R^{2}=0.818, P<0.0001
$$

With $(\mathrm{R} 2=0.802, \mathrm{P}<0.0001)$ is more accurate in relation to the degree, indicating that with the increase in the heart rate during physical activity, aerobic capacity is reduced.

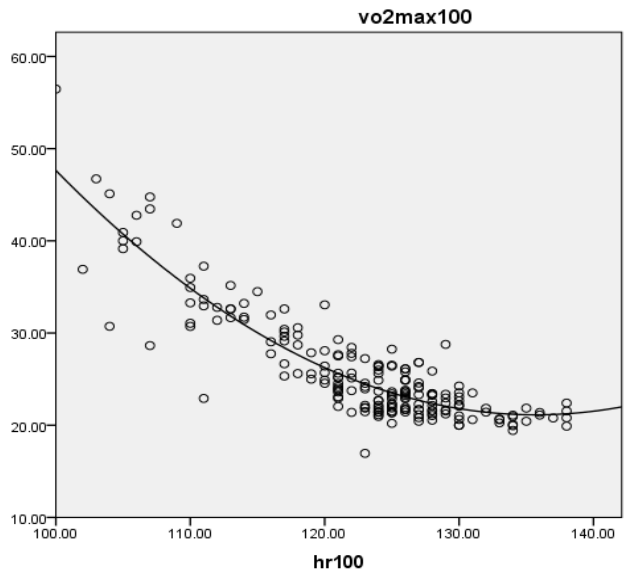

Figure 3: The association between HR and VO2max at the end of $\min .3(n=196)$

$$
R^{2}=0.802, P<0.0001
$$

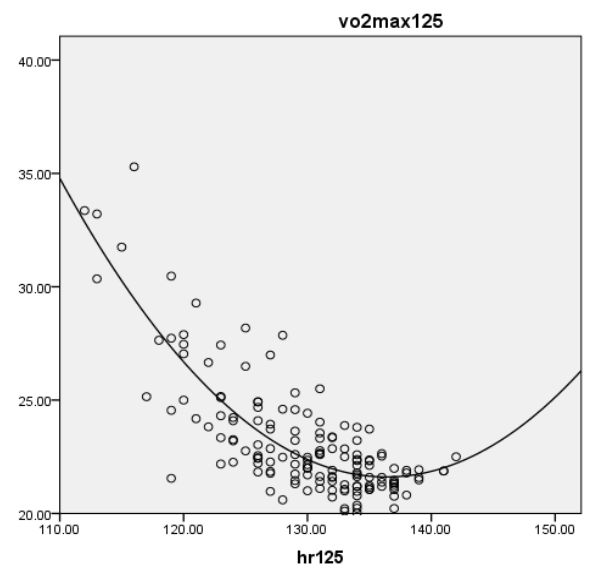

Figure 4: The association between HR and VO2max at the end of min. $4(n=150)$

$$
R^{2}=0.677, P<0.0001
$$

\section{Discussion}

The current study aimed to investigate the relationship between the aerobic capacity and 
the heat rate (HR) of the 200 male workers from metal components manufacturers (industry workers) in Isfahan. The participants were selected by using random sampling based on statistic method $(n=200)$. The results indicated that there is a strong significant relationship between the aerobic capacity and the heart beat.

In this study VO2max was predicted by equation based on heart rate recovery. Heart rate has been used in many articles for Assessment of physical workload (23), mental workload (24), fatigue (25), rating of perceived exertion (26) and etc which Indicates the accuracy of heart rate as a physiological factor. In our study, Pearson correlation showed a significant association between the aerobic capacity and heart rate during the different moments of the test (Table 2). Pearson correlation between mean heart rate and the aerobic capacity was equal to - 0.938, illustrating a significant association between these two variables. Furthermore, the results were in agreement with the study of Artes et al (27) using ergometer, and also results of Esposito et al which was done on the athletes using the HR as a measure for assessing the aerobic capacity (28). Results of this study with the internal investigation of Eizadi et al on 25 Adolescent corresponds (6) in the other study found a nonlinear relationship between $\mathrm{VO} 2$ and HR averaged over the subjects (29). On the other hand, in a study conducted on children, the heart rate was a factor used to estimate aerobic capacity (30). Even in UK, according to a study on men, heart rate with age is a determining factor to estimate aerobic capacity (31) In the study of vema et al to estimates the aerobic capacity, several different techniques were used in which the heart rate was measured during the work activity and it has been one appropriate technique for estimating aerobic capacity (32). So that a study in 2012, conducted by
Malek Mohamed et al on the patients, the significant correlation between two factors has not been observed. Perhaps, it is due to Brady Arrhythmia (33).

\section{Conclusions}

Determination of aerobic capacity is important in the discussion of health promotion and the prevention of occupational physical problems. Further, estimation of the aerobic capacity requires expensive and sophisticated laboratory equipment which is not affordable for the industry.

The results indicate a significant relationship between the heat rate (HR) and the aerobic capacity. Therefore, using the extended regression equation, it is possible to readily assess the aerobic capacity with no expensive laboratory equipments. Finally, the measured $\mathrm{VO} 2 \mathrm{max}$ is used to monitor the changes in the physical ability of workforce, plan for preventative actions, the required periodic examinations and, etc.

\section{Acknowledgments}

We most appreciate all the participants of this research. The study was supported by the Isfahan University of Medical Science.

Conflict of interest: Non declared

\section{References}

1. Daneshmandi H, Choobineh A, Rajaei-Fard A. Estimation of aerobic capacity and determination of its associated factors among male workers of industrial sector of Shiraz City, 2010. Iran Occupational Health 2011; $8(3): 48-58$.

JOHE, Winter-spring 2013; 2 (1-2) 
2. Daneshmandi H, Choobineh AR, RajaeeFard AR. Validation of Borg's RPE 6-20 Scale in Male Industrial Workers of Shiraz City Based on Heart Rate. Jundishapur Sci Med J 2012; 11(1):1-10.

3. Chen M, Fan X, Moe S. Criterion-related validity of the Borg ratings of perceived exertion scale in healthy individuals: a metaanalysis. Journal of sports sciences. 2002;20(11):873-99

4. American College of Sports Medicine (2003). ACSM fitness book. $3^{\text {nd }}$ ed. California: Human Kinetics. P184.

5. Capodaglio EM. Comparison between the CR10 Borg's scale and the VAS (visual analogue scale) during an arm-cranking exercise. J Occup Rehabil 2001; 11(2):69-74.

6. Eizadi M, Shafiei M, Zahedmanesh F, Afsharmand Z. Maximal heart rate percentage in relation to maximal oxygen consumption percentage in spastic patients. Ann Biol Res 2011; 2(6):635-41.

7. Foster PP, Feiveson AH, Genhardt ML, Schneider SM. [abstract] Oxygen uptake and heart rate relationship in dual- cycle maximal exercise. Undersea and Hyperbaric Medical Society, Inc [Internet] 2000. Available from: http://archive.rubicon-foundation.org/5351

8. Brake DJ. The deep body core temperatures, physical fatigue and fluid status of thermally stressed workers and the development of thermal work limit as an index of heat stress $[\mathrm{PhD}$ thesis]. Western Australia: Curtin University of Technology; 2002.

9. Mocková K, Radvanský J, Matouš M. Vztah odhadnuté intenzity zátěže (RPE-Rating of Perceived Exertion) $\mathrm{k}$ tepové frekvenci, spotřebě kyslíku a zátěži u pacientů léčených beta-blokátory sympatiku. Med Sport Boh Slov. 2000; 9(2):58-67.

10. George JD, Stone WJ, Burkett L. Nonexercise VO2max estimation for physically active college students. Medicine and science in sports and exercise. 1997;29(3):415-23.

11. Brake DJ. The deep body core temperatures, physical fatigue and fluid status of thermally stressed workers and the development of thermal work limit as an index of heat stress [PhD thesis]. Western Australia: Curtin University of Technology; 2002.

12. Weiser PC, Stamper DA. (1977). Psychophysiological interactions leading to increased effort, leg fatigue, and respiratory distress during prolonged, strenuous bicycle riding. In: Physical work and effort. USA, Colorado: National Asthma Center. P401-16.
13. Habibi E, Soleymanei B, Nateghei R, Lotfirosbehani M, Yarmohammadian $M$, Lotfi M, et al. Risk management in radiology units of Isfahan University of Medical Sciences' hospitals. Health Information Management 2007; 4(1):133- 41.

14. Cink RE, Thomas TR. Validity of the Astrand-Ryhming nomogram for predicting maximal oxygen intake. Br J Sports Med 1981; 15(3):182-5.

15. Habibi E, Soleymanei B, Nateghei R, Lotfirosbehani M, Yarmohammadian M, Lotfi M, et al. Risk management in radiology units of Isfahan University of Medical Sciences' hospitals. Health Information Management 2007; 4(1):133- 41.

16. Cink RE, Thomas TR. Validity of the Astrand-Ryhming nomogram for predicting maximal oxygen intake. Br J Sports Med 1981; 15(3):182-5.

17. Greiwe JS, Kaminsky LA, Whaley MH, Dwyer GB. Evaluation of the ACSM submaximal ergometer test for estimating VO2max. Med Sci Sports Exerc 1995; 27(9):1315-20.

18. Siconolfi SF, Cullinane EM, Carleton RA, Thompson PD. Assessing VO2max in epidemiologic studies: Modification of the Astrand-Rhyming test. Med Sci Sports Exerc 1982; 14(5):335-8.

19. Deakin GB, Davie AJ, Zhou Sh. Reliability and validity of an incremental cadence cycle VO2max testing protocol for trained cyclists. J Exerc Sci Fit 2011; 9(1):31-9.

20. Buckley JP, Sim J, Eston RG, Hession R, Fox R. Reliability and validity of measures taken during the chester step test to predict aerobic power and to prescribe aerobic exercise. Br J Sports Med 2004; 38(2):197205.

21. Karvelas BR, Hoffman MD, Zeni Al. Acute effects of acupuncture on physiological and psychological responses to cycle ergometry. Arch Phys Med Rehabil 1996; 77(12):12569.

22. Schmitz KH, Courneya KS, Matthews C, Demark-Wahnefried W, Galvão DA, Pinto $\mathrm{BM}$, et al. American college of sport medicine roundtable on exercise guidelines for cancer survivors. Med Sci Sports Exerc 2010; 42(7):1409-26.

23. Dwyer G, Davis SE (2008). ACSM's healthrelated physical fitness assessment manual. $2^{\text {nd }}$ ed. USA: Wolters Kluwer ILIppincott Williams \& Wilkins. P11-124. 
24. Arts FJ, Kuipers H, Jeukendrup AE, Saris WH. A short cycle ergometer test to predict maximal workload and maximal oxygen uptake. Int J Sports Med 1993; 14(8):460-4.

25. Meshkati N. Heart rate variability and mental workload assessment. Advances in Psychology 1988; 52:101-15.

26. Segerstrom SC, Nes LS. Heart rate variability reflects self-regulatory strength, effort, and fatigue. Psychol Sci 2007; 18(3):275-81.

27. Gamberale F. Perceived exertion, heart rate, oxygen uptake and blood lactate in different work operations. Ergonomics 1972; 15(5):545-54.

28. Arts FJ, Kuipers H. The relation between power output, oxygen uptake and heart rate in male athletes. Int J Sports Med 1994; 15(5):228-31.

29. Esposito F, Impellizzeri FM, Margonato V, Vanni R, Pizzini G, Veicsteinas A. Validity of heart rate as an indicator of aerobic demand during soccer activities in amateur soccer players. Eur J Appl Physiol 2004; 93(1-2):167-72.

30. Jacks DE, Topp R, Moore JB. Prediction of VO2 peak using a sub-maximal bench step test in children. Clinical Kinesiology 2011; 65(4):68-75.

31. Faulkner J, Parfitt G, Eston R. Prediction of maximal oxygen uptake from the ratings of perceived exertion and heart rate during a perceptually-regulated sub-maximal exercise test in active and sedentary participants. Eur J Appl Physiol 2007; 101(3):397-407.

32. Vema JP, Sajwan AS, Debnath M. A study on estimationg $\mathrm{VO} 2 \mathrm{max}$ from different techniques in field situation. International Quarterly of Sport Science 2009; 2:42-7.

33. Malekmohammad M, Ahmadi-Nejad M, Adimi P, Jamaati HR, Marashian SM. Evaluation of maximum $\mathrm{O} 2$ consumption: Using ergo-spirometry in severe heart failure. Acta Med Iran 2012; 50(9):619-23. 